\title{
ENHANCING CREATIVITY AND TECHNICAL COMPETENCE FOR DESIGN STUDENTS USING VIRTUAL REALITY TOOLS
}

\author{
Mehran KOOHGILANI and Richard GLITHRO \\ Bournemouth University
}

\begin{abstract}
Teaching large groups of varying abilities and course ideologies has always been a problem. Many tools have been implemented and suggested over time. The paper highlights these tools and then sets the scene for the use of Virtual Reality and why it is the tool to use. This paper will look at how VR, through case studies, has been used to enhance the teaching and learning of Design and Engineering students. The pitfalls and the lessons learnt which would feed into the next iteration of the process. A discussion of the relationship of these tools and nurturing creativity is also included in the study. It is always, envisioned at the start, what would the ideal platform and outcome should be and then reflect critically on what was achieved because it was achievable.
\end{abstract}

\section{Keywords: Virtual reality, teaching pedagogies, creativity, user experience}

\section{INTRODUCTION}

There is large gap between what is taught and expected at school and that of universities and the commercialization pressures and income models adopted by universities, has necessitated large support mechanisms in order to achieve retention and progression. Many new post 1992 universities think of this as added value. Many scholars have studied retention and have made recommendations. Many new approaches have been around using the power of internet and online courses. According to Meloni [1] different instructors define "teaching online" and "teaching with technology" differently. Technologies implemented range from using presentations such as PowerPoint to using blogs and flipped classrooms. Platforms such as blackboard, Moodle and Brightspace have been used. However, the need for that face to face still exist and the course has still to be delivered by the lecturer. In fact, without the interaction of the students with the lecturer, failure will be inevitable. This is one of the reasons why, despite the abundance of freely available YouTube videos on various topics, many students still struggle with assessments. Semi-structured interviews with lecturers through questionnaires were used by Gow \& Kember [2] to investigate the relationship between parallel teaching and the student learning. Hurson and Kavi [3] have discussed the rise in higher education costs in relation to the demands for computer specialists and the shortage of expertise in offering technology-oriented courses. They observed that most students absorb and retain visual material more readily. There are of course ear-learners and the ones who learn by physical practice. According to them about $20 \%$ of what is heard retained compared to $40 \%$ of what is seen as well as heard. The ideal is $75 \%$ of what is seen, heard, and experienced. This is something which cannot realistically be achieved in the traditional classroom settings with large numbers, cross disciplinary, and only hour long. As can be imagined a typical lecture would possibly contain videos, slide presentation, chalk and talk as well question and answers. Technology has enabled interactive computer courses which offer all three modes of learning. Of course, they recognise that it is important for the student to embrace the interactivity of the lecture.

According to Ausburn et al [4] virtual Reality has been defined in many different ways and now means different things in various contexts. They discuss the benefits of using visual technologies for teaching and learning in industrial education. The capabilities and possibilities for VR technology may open doors to new vistas in industrial and technical instruction and learning. The emergence of desktop VR has made it possible for industrial educators to add this powerful high-impact technology to their classroom instructional mix, and to build a unique research base in the field. Desktop VR may be a technology whose time has come for both research and practice in industrial education. With recent 
breakthroughs in technical and cost accessibility, the door to the world of virtual reality is standing wide open. The also discuss the implications and recommendations for the use of VR technology as a potential tool for technical and industrial training. Hoffman and $\mathrm{Vu}[5]$ have recognised Virtual reality (VR) for its enormous educational potential. They talk of VR technologies being designed to provide engaging and intuitive environments for learning visually and spatially complex topics such as human anatomy, biochemistry, and molecular biology. These new systems promise to make broad-based training experiences available for students at all levels, without the risks and ethical concerns typically associated with using animal and human subjects. Medical students could acquire proficiency and gain confidence in the ability to perform a wide variety of techniques long before they need to use them clinically. Surgical residents could rehearse and refine operative procedures, using an unlimited pool of virtual patients manifesting a wide range of anatomic variations, traumatic wounds, and disease states. Those simulated encounters, in combination with existing opportunities to work with real patients, could increase the depth and breadth of learners' exposure to medical problems, ensure uniformity of training experiences, and enhance the acquisition of clinical skills. Ortiz et al [6] have proposed the implementation of a virtual tool applied to the field of Automotive Engineering, with the aim of strengthening the processes of teaching-learning, so that the student can achieve meaningful learning. Their system consists of the implementation of a virtual automotive laboratory, in which one can take guided classes, specific practices and evaluations in the automotive field, allowing greater immersion and interaction during the teaching-learning process in order to optimize resources, materials, infrastructure, time, among other benefits. The system would allow the ability to select the working environment and the level of difficulty during the teaching-learning process. Their results show this tool to very versatile and can be extended to other areas. It can motivate the students and facilitate the incorporation and presentation of new elements to develop new practices. According to Horváth [7] from an educational perspective, an important benefit brought about by such technologies as VR is that they lead to a teaching environment that is first and foremost learner centred. This encourages the application of innovative educational methods and introduces new modes of teaching into the learning experience. However, all of this makes it necessary for teachers to spend more time preparing for their classes, as well as growing acquainted with the latest technologies - in short, it is a process that requires improved digital literacy on the teachers' part. Horváth presents an experiment contrasting traditional 2D interfaces and the MaxWhere 3D VR educational platform in order to shed light on how these technologies influence the effectiveness of various operations and workflows constituting teachers' tasks. In the experiment, the same workflow is compared when executed using e-mail attachments, a classical 2D e-learning platform and MaxWhere's 3D platform. The results of the experiment, evaluated in terms of a newly proposed (and clearly motivated) framework, point to the conclusion that when using MaxWhere instead of traditional 2D interfaces, teachers, lecturers, and trainers are able to accomplish the same digital workflows with $37-64 \%$ less user operations, and up to $72 \%$ less machine operations. Based on these results, the paper concludes that MaxWhere as an educational platform offers users - not only students, but the lecturers, teachers, and trainers too- a number of ways to accomplish tasks that would otherwise require extremely complicated digital workflows in more traditional 2D environments. Kurilovas [8] has analysed the problem of quality evaluation and personalisation of virtual reality/augmented reality/mixed reality (VR/AR/MR). First of all, systematic review of relevant scientific literature on the research topic was conducted. After that, findings of the systematic review concerning evaluation of quality and personalisation of VR/AR/MR learning environments are presented. Kurilovas' VR/AR/MR learning systems/environments quality evaluation and personalisation framework is also presented in the paper. Evaluation of quality of VR/AR/MR platforms/environments should be based on (a) applying both expert-centred (top-down) and usercentred (bottom-up) quality evaluation methods and (b) separating 'internal quality' criteria, and 'quality in use' criteria in the set of quality criteria (model). Personalisation of $V R / A R / M R$ platforms/environments should be based on learners' models/profiles using students' learning styles, intelligent technologies, and Semantic Web applications. As expected according to Male et al [9] safety in design is an important topic in engineering education for which practical experiences are likely to be beneficial but logistically difficult, and high risk. They show that Virtual reality (VR) offers the possibility for students to learn from an interactive experience without the inconveniences and safety hazards in real site visits. One of the challenges of using VR has been providing learning experiences to large classes of students. This investigated the efficacy of VR for teaching safety in design, and an approach to accommodate VR with large numbers of students. Students learned about safety in design 
in workshops, using a VR environment. They worked in groups in which only one member wore the VR headset and others observed. They found that students agreed that they identified additional risks after the VR experience regardless of whether they wore the headset. One interesting side observation was that usually quiet students, who were often international students, participated more actively in the group discussions than in their usual weekly group meetings.

Setozaki et al [10] have examined the practical use of screen presentation systems. At first, they developed Multi aspect VR teaching material, and the presentation system was improved. The teaching material produced using this system was then brought to and used in a high school. They taught lessons using the VR. This made a good impression on the students in the class. The students were compelled to get involved in the class. According to Cooper et al [11] Virtual reality (VR) platforms act as a potentially transformative tool in learning and teaching. They examined pre-service teachers' (PST) perceptions about VR, inclusive of their beliefs about its capacity to be used as a teaching and learning tool. They conducted a case study at an urban university in Australia involved 41 participants. Participants' positive perceptions of VR in their teaching relate to its potential to engage learners, the immersive potential of the platform and the scope of VR to offer students experiences they might otherwise not have with other learning tools. Concerns expressed by PSTs include their relatively low self-efficacy to use VR in their teaching, monitoring-related matters, financial cost and implementing the technology in a safe and supportive way. There was a significant difference in PSTs' amount of selfefficacy to teach using VR when compared to their overall confidence to use digital technologies. PSTs typically had greater awareness of the immersive and engagement potential of VR and less awareness about its potential to foster and promote collaborative learning. This paper contributes to an emerging discourse regarding the possible applications of VR in educational environments and particularly in relation teacher-educator contexts. According to Hutchison [12] evolving digital technologies has provided opportunities to engage students in activities that go beyond print-based reading and writing and help them develop skills for reading, writing, and communicating with digital technology. Virtual reality apps are a rapidly emerging form of digital technology that provides immersive experiences in real or imagined environments. Virtual reality creates sensory experiences that involve sight, touch, hearing, and motion to allow users to feel as though they are physically present in that environment. These types of immersive experiences can be used to engage learners in multimodal literacy practices as well as scientific practices such as forming hypotheses and interpreting data to inform courses of action. The author provides a classroom example of using virtual reality in an integrated science and literacy lesson to engage students in discovering, answering, and writing about questions they developed as they explored a virtual environment. Williams and Alrmuny [13] have explored the utility of the virtual reality technology for the purpose of developing visual literacy and understanding about the microscopic world as it relates to the macroscopic properties of matter. Additionally, it shares perspectives of education students in various teacher preparation disciplines about virtual reality as an instructional tool. Through a mixed-method design, pre/post data and interview transcripts provide insight into the VR program and its bearing on learning. Tsuji et al [14] know that it is difficult to understand nursing practically for students who have just started studying nursing, because they cannot imagine the actual medical scene. The authors expected that they could improve nursing learning through experiences in virtual medical environments supported by ICT (information and communication technology). They have developed teaching materials in nursing education, and in a previous study reported that the use of a virtual hospital was useful for students who had not had medical experience. Their aim was to have students consider the meaning of a hospital room ceiling. First, they showed them a few ceiling patterns, and they selected the best one among the patterns. After that, they showed the same one in a virtual hospital room. They had negative opinions about what they had thought was the best one at this time. This demonstrated that the virtual hospital room is effective when students evaluate the ceiling as a part of the hospital room. Martín-Gutiérrez et al [15] state that Virtual reality captures people's attention. This technology has been applied in many sectors such as medicine, industry, education, video games, or tourism. Perhaps its biggest area of interest has been leisure and entertainment. Regardless the sector, the introduction of virtual or augmented reality had several constraints: it was expensive, it had poor ergonomics, or implied too much work to create contents. Recent technological innovations, including the rapid adoption of smartphones by society, have facilitated the access to virtual reality and augmented reality of anyone. In addition, several large companies like Apple, Facebook, Samsung, and Magic Leap, among others, have increased their investment to make these technologies to improve their accessibility within the next few years. 
Educational institutions will benefit from better accessibility to virtual technologies; this will make it possible to teach in virtual environments that are impossible to visualize in physical classrooms, like accessing into virtual laboratories, visualizing machines, industrial plants, or even medical scenarios. The huge possibilities of accessible virtual technologies will make it possible to break the boundaries of formal education. Nelson and Ahn [16] recognize that there has been a growing need to teach professional development skills to engineering students at Iowa State University. Students are often lacking these skills even though they are desired skills to have both for academic success and in the workplace. They explored using virtual reality to teach four professional development skills to students. These skills are leadership, teamwork, communication, and ethics. Virtual reality as an innovative tool was used to teach students these skills in an interactive and fun environment. Fernandez [17] presents and discusses the developing role of virtual and augmented reality technologies in education. Addressing the challenges in adapting such technologies to focus on improving students' learning outcomes, the author discusses the inclusion of experiential modes as a vehicle for improving students' knowledge acquisition. Stakeholders in the educational role of technology include students, faculty members, institutions, and manufacturers. While the benefits of such technologies are still under investigation, the technology landscape offers opportunities to enhance face-to-face and online teaching, including contributions in the understanding of abstract concepts and training in real environments and situations. Barriers to technology use involve limited adoption of augmented and virtual reality technologies, and, more directly, necessary training of teachers in using such technologies within meaningful educational contexts. The author proposes a six-step methodology to aid adoption of these technologies as basic elements within the regular education: training teachers; developing conceptual prototypes; teamwork involving the teacher, a technical programmer, and an educational architect; and producing the experience, which then provides results in the subsequent two phases wherein teachers are trained to apply augmented- and virtual-reality solutions within their teaching methodology using an available subject-specific experience and then finally implementing the use of the experience in a regular subject with students. The essay concludes with discussion of the business opportunities facing virtual reality in face-to-face education as well as augmented and virtual reality in online education. Davies et al [18] present their initial experiences integrating virtual reality (VR) $360^{\circ}$ viewable images within a university medical imaging teaching session and some general transferable learning points for the successful delivery of VR content. VR has the potential to offer students an immersive educational experience but is not without its limitations. Our initial experience using VR with small groups $(n<7)$ and larger groups $(n<35)$ highlighted several obstacles which needed to be overcome to be able to successfully use VR in teaching. They found that requiring students to use their own devices to view VR content during teaching sessions (downloading the media content and loading it into a suitable app for viewing) presented a variety of problems, with pilot studies only a limited number of students successfully engaged with the VR content. The problems faced by students were a result of device compatibility (such as software versions, sensor capability such as lack of accelerometers), storage limitations app and browser capabilities (e.g., $360^{\circ}$ video on YouTube is currently not supported by the Safari browser). The physical device size, button location and screen brightness caused issues when attempting to use some phones in consumer VR headsets. A diversity in student's digital fluency impacted on the level of student support required in the classroom to ensure engagement, and also made the activity highly labour intensive.

\section{CASE STUDY}

An existing undergraduate workshop skills project was used as the foundation of the VR experience. Students were required to manufacture and assemble a simple oscillating engine from engineering drawings and operation sheets (Figure 1) that focused upon milling and turning operations. In previous years students had experienced difficulties interpreting the engineering drawings of the project in addition to issues with the order of assembly of the final components. 


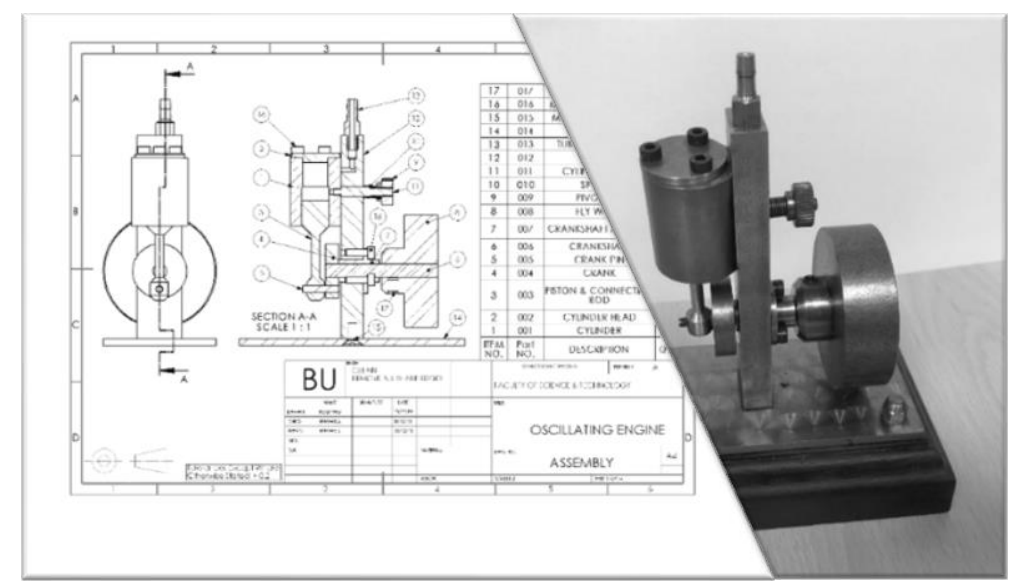

Figure 1. Oscillating Engine

The VR experience aimed to address both issues by providing a scaled up virtual version of the assembly that contained three sections (Figure 2); the first was an assembled version of the oscillating engine, the second was all components laid out for the student to view and the third an animated exploded version of the assembly.

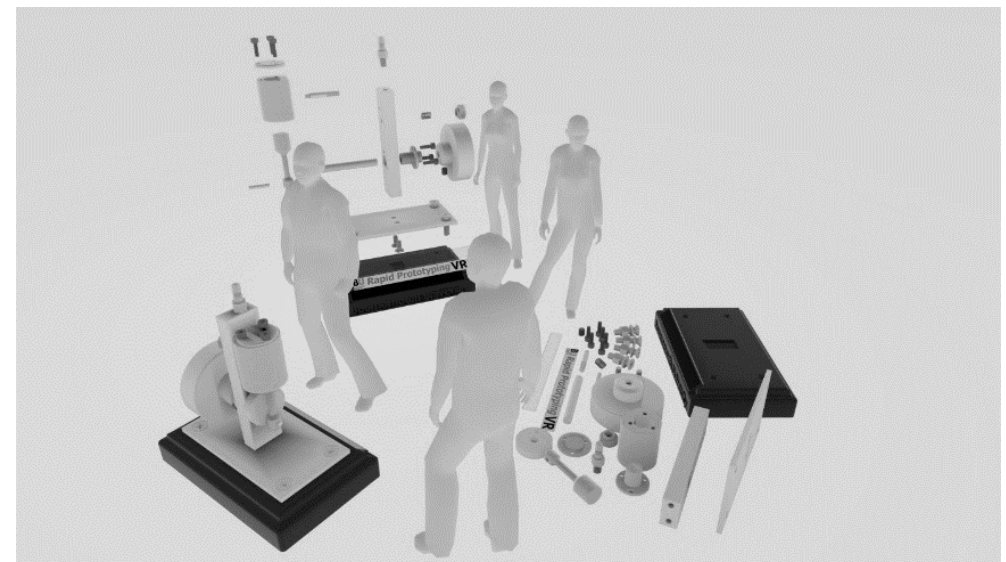

Figure 2. VR Layout and Relative Scale

The students were given access to the VR scene at the same time they started on the physical components, they were given approximately 5 mins to view the scene and watch the animation. Engagement was varied, some students stood still and just looked around the scene whilst other became fully engaged in the virtual environment and were happy to walk around and crouch down to examine specific components in detail.

Overall, the verbal feedback from the students on the experience was very positive the animated view and the scaled-up model were the items most talked about by the students during and after the experience. When returning to the workshop the students found it easier to understand the relationship between the different components and how they fit together in the assembly.

\section{DISCUSSION}

VR has great potential as a tool to integrate into the design process as it can bridge the gap between a two-dimensional screen and physical prototype. The ability to scale models has been highlighted by participants as a valuable part of the experience. Future work: in order to fully immerse the students in the virtual world scene interactivity needs to be explored, in this case study the student was just an observer rather than an active participant. Future projects would look to allow for the construction of the assembly in VR in order to make a more immersive experience. This would need to be balanced against resources available and the space required if the student's VR time were to be extended. 


\section{REFERENCES}

[1] Meloni J. Technologies for Teaching: Strategies and Pitfalls, Education Digest, April 2011, Vol. 76, No. 8, pp 23-27.

[2] Gow L. and Kember D. Conceptions of teaching and their relationship to student learning. British Journal of Educational Psychology, 1993 (Online 2011), Volume 63, Issue 1, pp. 20-23.

[3] Hurson A. R. and Kavi K. M. Interactive Teaching Practices in Small Class Sizes while Cutting into the High Cost of Education. http://mcs.open.ac.uk/bp5/papers/1997-EdMedia/ed-mediatutorials.pdf [Accessed on 2020, 3 February].

[4] Ausburn L. J. and Ausburn F. B. Desktop Virtual Reality: A Powerful New Technology for Teaching and Research in Industrial Teacher Education. Journal of Industrial Teacher Education, Win 2004, v41 n4, 1-16.

[5] Hoffman H. and Vu D. Virtual reality: teaching tool of the twenty-first century? Academic Medicine: Journal of the Association of American Medical Colleges, 1997 Dec, 72(12)

[6] Ortiz J. S., Sánchez J. S., Velasco P. M., Sánchez C. R., Quevedo W. X, Zambrano V. D., Arteaga O. and Andaluz V. H. Teaching-Learning Process through VR Applied to Automotive Engineering, ICETC 2017: Proceedings of the 2017 9th International Conference on Education Technology and Computers, December 2017 pp36-40.

[7] Horváth I. Evolution of teaching roles and tasks in VR / AR-based education, 2018 9th IEEE International Conference on Cognitive Infocommunications (CogInfoCom), Budapest, Hungary, 2018, pp. 000355-000360.

[8] Kurilovas E. Evaluation of quality and personalisation of VR/AR/MR learning systems, Behaviour \& Information Technology, 2016, 35:11, pp. 998-1007.

[9] Male S. A., Kenworthy P., Hassan G. M., Guzzomi A., Van der Veen T. and French T. Teaching safety in design in large classes using VR [online]. In: 29th Australasian Association for Engineering Education Conference, 2018 (AAEE 2018). Hamilton, New Zealand: Engineers Australia, pp. 459-465.

[10] Setozaki N., Morita Y. and Takeda T. Examination for the Practical Use of Screen Presentation Systems and VR Teaching Material. In Carlsen R., McFerrin K., Price J., Weber R., and Willis D. (Eds.), Proceedings of SITE 2007--Society for Information Technology \& Teacher Education International Conference, 2007, San Antonio, Texas, USA: Association for the Advancement of Computing in Education (AACE), pp. 3488-3494.

[11] Cooper G., Park H., Nasr Z., Thong L. P., and Johnson R. Using virtual reality in the classroom: preservice teachers' perceptions of its use as a teaching and learning tool, Educational Media International, 2019, 56:1, 1-13.

[12] Hutchison A. Using Virtual Reality to Explore Science and Literacy Concepts, The Reading Teacher, 2018, Vol. 72 No. 3 pp. 343-353.

[13] Williams M. K. and Alrmuny D. Teaching How to Visualize the Invisible: Using Virtual Reality to Expose the Microscopic World of Chemistry. In K. Graziano (Ed.), Proceedings of Society for Information Technology \& Teacher Education International Conference, 2019, Las Vegas, NV, United States: Association for the Advancement of Computing in Education (AACE), pp. 178181.

[14] Tsuji K., Iwata N., Kodama H. et al. Development of Teaching Materials in Basic Nursing Using Virtual Reality - Ceiling Image Teaching Materials of a Hospital Roo, Journal of Uoeh. 2017; 39(1), pp. 63-68.

[15] Martín-Gutiérrez J., Efrén Mora C., Añorbe-Díaz B. and González-Marrero A., Virtual Technologies Trends in Education, EURASIA Journal of Mathematics Science and Technology Education, ISSN 1305-82231305-8215, 2017 13(2), pp. 469-486.

[16] Nelson M. E. and Ahn B. "Virtual Reality Activities for Teaching Engineering Students Professional Development Skills," 2018 IEEE Frontiers in Education Conference (FIE), San Jose, CA, USA, 2018, pp. 1-5.

[17] Fernandez M. Augmented Virtual Reality: How to Improve Education Systems Higher Learning, Research Communications, Jun 2017, v7 n1 pp. 1-15.

[18] Davies A. G. Crohn N. J. and Treadgold L. A. Can virtual reality really be used within the lecture theatre? BMJ Simulation and Technology Enhanced Learning, 2019, 5, pp. 234-235. 